\title{
HOW DO ONLINE STUDENTS DIFFER FROM LECTURE STUDENTS?
}

\author{
John Dutton \\ College of Management \\ North Carolina State University \\ PO Box Dutton 7229 \\ Raleigh, NC 27695-7229 \\ Phone: 919-515-6948 \\ Fax: 919-515-6943 \\ Email: john_dutton@ncsu.edu \\ Marilyn Dutton \\ School of Business \\ North Carolina Central University \\ Durham, NC \\ Jo Perry \\ TogetherSoft Corporation \\ Raleigh, NC
}

\begin{abstract}
This study has two primary objectives. First, we want to know how students who enroll in online classes differ from their peers in traditional lecture classes. Our second objective involves both exploring what factors influence performance among online students, as well as whether those factors differ for online and lecture students. Our comparisons are of two large sections of a course in computer programming for which almost the only difference was that one section consisted of on-campus lectures, and the other section was online. We find that online students do differ from lecture students in a number of important characteristics. However, when we examine class performance and course completion, we find that the factors which influence performance seem to have a stronger impact on lecture students, but we cannot reject the hypothesis that factor coefficients are the same for the two groups.
\end{abstract}

\section{KEY WORDS}

Learning effectiveness, Access, Student satisfaction, Distance education, Internet

\section{INTRODUCTION}

Use of the internet for educational purposes is widespread and rapidly growing. Thousands of university courses have been developed for delivery entirely via the web. This trend will only accelerate as more colleges and universities urge faculty to create online versions of their courses. 
Some university faculty members are strong proponents of internet use. They believe web-based courses can provide educational opportunities to students who would otherwise have to do without, and they believe those courses can be of a quality comparable to traditional lecture courses. At the same time there are many university faculty members who are suspicious of such courses and have significant doubts about a medium that does not include face-to-face contact between instructor and student. Perhaps because of this concern, the majority of research has focused on determining whether students perform as well in online classes. In fact, comparisons of online and traditional lecture formats indicate that, on average, students perform at least as well in classes with an online component [1], [2], [3], [4], [5], [6], [7]. Moreover, there is evidence that student ratings of various aspects of courses are also similar for online and lecture modes [8].

This paper is an extension of previous work that we have done in the area of online delivery. In an earlier paper we demonstrated that students taking an entirely web-based course perform as well as or better than students taking the same course in a traditional lecture format [3]. We compared two sections of the same computer science course, taught side-by-side by the same instructor and graded in the same way. Our findings showed that students in the online section learned as much as their traditional lecture counterparts, as demonstrated by somewhat better examination and course grade scores. However, although the average course grades were at least as good, the online students were less likely to complete the course. The higher dropout rate for online classes has also been noted by other researchers [9].

In this paper we extend and broaden our earlier investigation to address two additional questions in online education. The first question asks who is likely to take online classes. It would be useful to know how students who enroll in online classes differ from their peers in traditional lecture classes. One might expect these students to display certain distinguishing characteristics that would lead them to enroll in online classes.

Secondly, we ask what factors influence performance among online students and whether those factors might differ for online and lecture students. One reason for our interest in this issue is the higher dropout rate for students in the online section, which we observed in our previous study. Information about success in online classes would prove useful for both guidance and course development purposes.

\section{DATA}

The data for this study were taken from two class sections of CSC114, Introduction to Programming in $\mathrm{C}++$, taught at North Carolina State University in the 1999 fall semester. At the time that we gathered these data, CSC114 was required for computer science majors, many engineering majors (such as those in electrical engineering), and some majors with technical components (such as those with management information systems). It was also required for the "Certificate in Computer Programming," a program for students with undergraduate degrees who wished to retrain for jobs as computer programmers. The total enrollment for the course was approximately 2000 students in the 1999 academic year. (As JAVA has grown in popularity, $\mathrm{C}++$ has become less prominent, so the class conditions have changed somewhat since 1999.)

The on-campus lecture sections of CSC114 met in two 50-minute lectures sessions with a once-per-week, three-hour structured lab. Classes were typically large, with 200 or more students, but the labs, which were taught mainly by undergraduates, were limited to 23 students each. Students' grades were based on the following scheme:

\section{- $10 \%$ Lab average}


- $5 \% \quad$ Small lab program average

- $5 \%$ Homework

- $30 \%$ Three programming projects

- $30 \%$ Three tests

- $20 \%$ Final examination

CSC114 went online in the fall of 1997, and it has been online every semester since. At the time of the class under study, it was the most popular online course at North Carolina State University, attracting 150 - 200 students each semester. Between 1997 and 1999, the online version was made progressively more accessible to off-campus students. Initially, it consisted of online lectures and course materials, but students were required to attend labs and take on-campus exams ( 3 during the semester and a final exam). In the spring of 1998, the lab was put online, and online students could choose to take the lab either online or on campus. Then in the spring of 1999, online students who could arrange for secure testing facilities were permitted to take their exams off campus as well, thus enabling students to take the entire course online.

The course website was complete and organized around the following pages:

- General Information: contained the instructor's name, office hours, email address, as well as required and recommended texts, the grading scheme, cheating policies, and expected workload.

- Bulletin: contained daily announcements that the on-campus instructor would typically make at the beginning of class. The announcements included such items as availability of programming projects, information regarding the next test, corrections to assignments, and adjustments in schedules.

- Lectures: contained links to all lecture material. Lectures were organized into 51 "Lessons," each designed to take approximately 20 minutes to complete. Each lesson had an introduction, explanation of the significance of the subject matter, examples, and applications. Several sound clips (for overviews, class commentary) and self-test questions with answers accompany each of the lessons.

- Regular and Online Labs: showed the schedule of lab work for the semester. The Online Lab pages also contained all of the lab materials and exercises. (Online labs were automatically graded by WebAssign $(\subset$, a homework and testing facility at North Carolina State University.)

- Assignments: contained links to all programming projects and short coding assignments. This page also instructed the students how to access their short answer homework, which was also graded by WebAssign $(\mathrm{C}$.

- Calendar: displayed a complete, day-by-day schedule for the semester, showing when lessons would be covered, as well as a list of dates for tests, projects, homework, and labs.

- Study Aids: contained links to tutorials and old tests. It also suggested some problem solving strategies for successfully completing assignments.

The only prerequisite for CSC114 was E115, a one-hour course in how to use popular applications on the campus workstations. This prerequisite was strictly enforced for students in the on-campus lab but not for those in the online lab because online students were assumed to have access to personal computers and be able to use them effectively. In order to participate in the online lab, students had to purchase and install MetroWerks CodeWarrior $\odot$, a multi-platform integrated $\mathrm{C}++$ programming development environment. In addition to E115, there was also a calculus co-requisite, but it was only casually enforced.

In most respects, the online version and the lecture version of CSC114 were virtually identical. The primary difference between the two was the lab, which necessarily varied according to the computing platform being used (Unix for lecture students, PCs or Macintoshes for online). However, online lab 
materials paralleled the lecture lab manual. In other respects, the two versions differed in only small details. The lecture students used the same website as the online students. They heard the same lecture as that presented in the website lessons. The two groups had the same homework and programming assignments and took the same tests, and both had access to a large bank of lab instructors who held regular office hours. However, the online lab instructors typically interacted with their students via email. Students in the lecture section had the same access as the online students to the website, but they could not join the online listserv, which was established to facilitate communication among the online students. Online students were allowed to attend the on-campus lectures (which usually provided additional examples and commentary on the lecture notes), but they rarely took advantage of this extra benefit.

Programming assignments constituted a substantial part of the overall course grades. Assignments had to be submitted electronically, and each assignment had an electronically set due time which made it impossible to submit "late" work without instructor intervention. Since the internet connections were not totally reliable (with server and ISP failures, for example), the online lab instructors were more generous in accepting "late" work than the lecture lab instructors. It was the responsibility of the online lab instructor to decide whether a student's failure to submit work on time was the fault of the student and then to respond accordingly.

At the beginning of the semester we administered a simple survey instrument to as many enrolled students as possible in the two class sections. The questionnaire (presented in the Appendix) collected information on work and childcare responsibilities, commuting distance and prior computer experience, as well as attitudes toward various aspects of the course. In addition, we were able to obtain information on the gender, age and university program of each student. As of the end of the official drop period (approximately one month after the beginning of the semester), the two sections of the class together contained 283 students, 152 in the lecture section and 131 in the online section. Of the 283 who remained in the course after the drop date, 237 students completed the course (took the final examination), and 46 did not.

Of the 283 who started the course, 193 completed usable surveys. Of these, 104 were enrolled in the lecture section and 89 in the online section. The response rate for both groups was $68 \%$. The survey response rates among those who finished the course and those who did not were $70 \%$ and $59 \%$. In statistical terms the two response rates were indistinguishable from each other.

\section{COMPARING ONLINE AND TRADITIONAL LECTURE STUDENTS}

In this section we examine the data to determine whether we can detect differences between online and lecture students. The information we have gathered from survey responses and student records breaks down into two major categories. The first class of information relates to the external, observable characteristics of the students. These include such things as age and gender, work, academic and childcare commitments commute distance and previous computer experience. The second information category contains preferences or considerations that are less easily observable by an outsider but may have influenced the student's choice of online versus lecture format. This set of information comes from the section of the survey that requests students to evaluate the importance of various issues in their choice of course format. These issues included such things as desire for interaction with the instructor and fellow students, concerns about scheduling conflicts and the way they characterize their own learning styles.

We examine first the external characteristics of the online versus lecture students. As with other forms of 
distance education, online classes can potentially make the university more accessible to mature students returning to school to update their current skills or acquire new ones [10]. In addition, these classes provide greater flexibility to students who benefit from being able to control the time during which they study the course materials [11]. If online classes do fulfill such needs, we would expect the online section to have more older and nontraditional students. We would also expect those students to have greater outside responsibilities than their peers in the lecture section.

To undertake such comparisons, we compute either group averages (when the variables can be quantified) or proportions (when we have only categorical responses). In order to determine whether the observed differences are meaningful, we perform statistical analysis on the data to measure significance. We use $t$ tests to evaluate differences between group averages when the variables are quantitative and chi-square tests for differences between proportions when the data are categorical. The p-value that comes out of each test is a handy measure of how meaningful any difference between the online and lecture sections actually is. This p-value is a probability measure and indicates the likelihood of obtaining the observed difference if in fact the characteristic were the same in the two sections. A low p-value implies that we would probably not observe such a large difference if the two sections were identical and we can therefore conclude that the difference is significant. We follow standard statistical convention and consider any difference with a p-value of 0.05 or less as statistically significant and any value less than 0.10 as marginally significant.

Table 1

Descriptive statistics for total sample and two subsamples

(P-values are for tests of equality of online and lecture statistics.)

\begin{tabular}{l|ccc|r} 
& Lecture & Online & \multicolumn{1}{c}{ Total } & \multicolumn{1}{c}{$p$-value } \\
\hline Number of responses & 152 & 131 & 283 & \\
\hline \% female & $20.4 \%$ & $20.6 \%$ & $20.5 \%$ & 0.9642 \\
Average age & 22.5 & 27.6 & 24.9 & $<0.0000$ \\
\% traditional undergraduate & $84.9 \%$ & $48.1 \%$ & $67.8 \%$ & $<0.0000$
\end{tabular}

Using the demographic data that we gathered from the student records, we are able to compare the online and lecture students along several dimensions. Table 1 presents percent female, percent traditional undergraduates, and average age for the online and lecture groups. Figure 1 augments the table with additional detail on age distribution. Just over twenty percent of the students in the whole sample were female and the percent female is almost exactly the same for the two sections. So, gender apparently played little role in the choice of course format. However, it is clear that older, non-traditional students prefer the online class. The average age of the online students was more than five years greater than that of the lecture students and Figure 1 shows that the distribution of age is almost exactly reversed in the two sections. Nearly two-thirds of the lecture section was less than 22 years old while the same proportion of the online section was older than 22. The composition of each section was also different. About twothirds of the whole sample were students officially enrolled in a traditional four-year undergraduate degree program at the university; the remaining one-third contained students of all other classifications including non-degree and post baccalaureate students and students working toward the certificate in computer programming, as well as a few graduate students. Yet only $48 \%$ of the online students were enrolled in an undergraduate program as opposed to nearly $85 \%$ of the lecture students. Both differences are large enough to be statistically significant. (The p-values associated with these two variables are smaller than 0.00005.) 


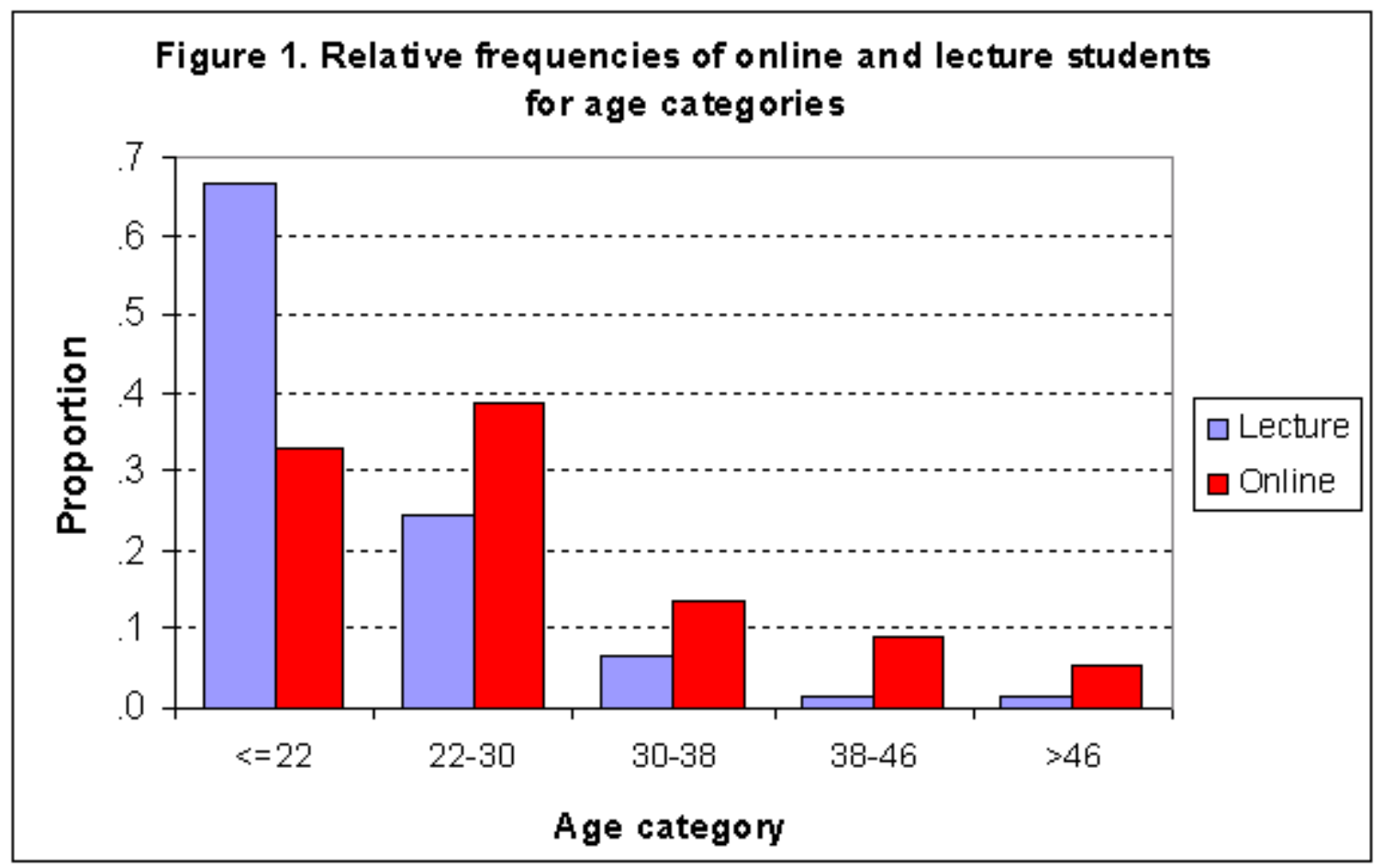

In addition to age and degree program, we were able to obtain information on the number of credit hours each student was carrying. From this we can see that the two sections appealed to different types of students. We divided the hours into four categories: 3 hours (representing students taking just this one course); $4-11$ hours (representing more than one course but less than full-time); $12-15$ hours (fulltime); and 16+ (overload). Figure 2 shows the distribution of students in each of the four categories of semester hours. It seems that the online section appealed to students who were not full-time ( $43 \%$ of the online students but only $9 \%$ of the lecture students were currently taking just this one course). In contrast, full-time students appear to have preferred the lecture section $(82 \%$ of the lecture students carried 12 or more semester hours while only $38 \%$ of the online students were full-time). 


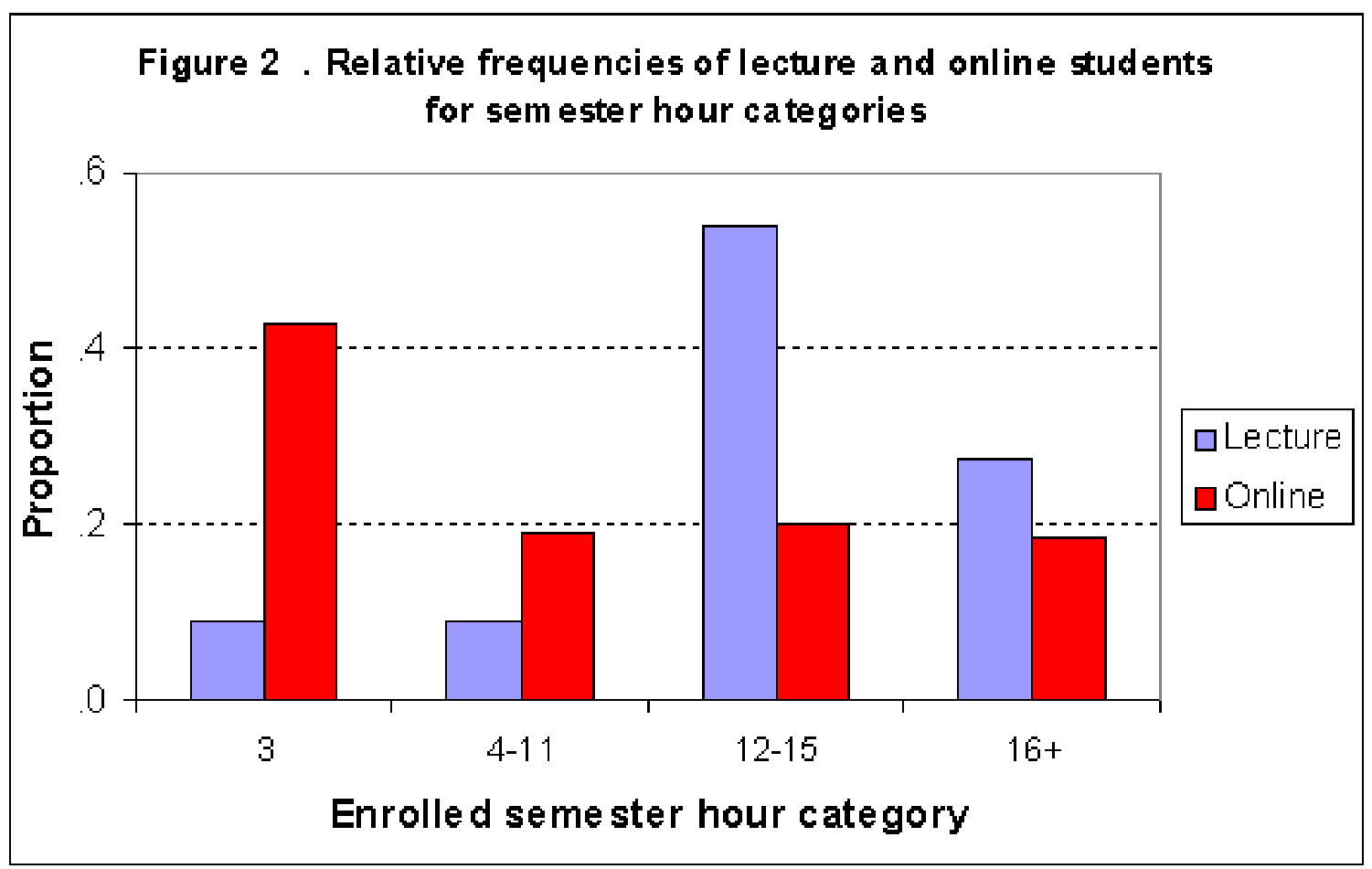

In addition to demographic characteristics, other life circumstances are also likely to differ across the two sections. A primary motivation for developing online classes has been to increase the convenience and flexibility of university study. Students who choose the online section are likely to be attracted for two major reasons:

- To avoid conflicts between class meetings and other responsibilities

- To avoid travel when the student's residence is far from campus

This leads us to expect that, on average, students taking the online section have greater outside responsibilities and that they live farther from campus. Three of our survey questions addressed these issues.

The two greatest responsibilities that students are likely to have outside of class are work and childcare. Our first two questions were designed to obtain information regarding these areas. We looked at work responsibilities in our first question: "Will you be working this semester?" Table 2 provides a breakdown of the responses. As we would predict, a far higher percentage of online students expected to work during the semester- $84 \%$ as opposed to $55 \%$ for lecture students. The p-value from the chi-square test shows this difference to be strongly significant. 
Table 2

Proportions planning to work, total and by section format

\begin{tabular}{l|ccc} 
& Lecture & Online & Total \\
\hline Responses & 104 & 89 & 193 \\
\% planning to work & $54.8 \%$ & $84.3 \%$ & $68.4 \%$
\end{tabular}

P-value for test of difference $=<0.0000$.

Not only were online students more likely to work, those who worked expected to be on the job more hours per week than the lecture students who worked. There were 128 respondents for the question relating to work hours (4 working individuals gave no hours). The averages presented in Table 3 indicate that online students who planned to work expected to put in almost twice as many hours per week as the lecture students. The difference in mean expected work hours is highly significant.

Table 3

Average hours per week, total and by section

\begin{tabular}{l|ccc}
\multicolumn{1}{c}{} & Lecture & Online & Total \\
\hline Number & 57 & 71 & 128 \\
Avg hrs/week & 20.5 & 37.7 & 30.0
\end{tabular}

P-value for chi-square test of difference $=<0.0000$.

The need to manage class requirements around childcare responsibilities might also draw students to online classes. We examined this in our second major question: "Will you have childcare responsibilities this semester?" Of the 193 respondents to the survey, only 20 reported childcare responsibilities. Of those, however, 13 were online students. The percentage of online students with childcare responsibilities was more than twice that of lecture students. The small number of students reporting childcare makes any statistical test less likely to be definitive. Nevertheless, the difference in proportions was marginally significant. We also asked for average hours of childcare per week, but the numbers of students reporting childcare were so small that we decided not to include those results as a considerable factor here. The small number of respondents in this category may be affected by the fact that women represented only $20 \%$ of the whole sample. In another situation, with more women, childcare responsibilities might be more common.

Table 4

Proportions with child care responsibilities

\begin{tabular}{l|ccc}
\multicolumn{1}{c}{} & Lecture & Online & Total \\
\hline Responses & 104 & 89 & 193 \\
$\%$ w/ child care & $6.7 \%$ & $14.6 \%$ & $10.4 \%$
\end{tabular}

$\mathrm{P}$-value for chi-square test of difference $=0.0735$

In addition to flexibility, online classes offer greater convenience since the class can literally be taken anywhere there is access to a computer. We would expect this feature to be relatively more attractive to students who find getting to campus a burden, either because of other responsibilities or because they live a greater distance from campus. To examine the commuting issue, our third major survey question was: "How many miles do you commute from your house to campus (one way)?" Because only 7 people answered "More than 50," we lumped them in with the next lower group to form a "More than 10" 
category. The results are shown in Table 5. The percentage of online students with a long commute is double the percentage for lecture students. The difference is statistically significant.

Table 5

\begin{tabular}{l|ccc}
\multicolumn{4}{c}{ Proportions commuting at least 10 miles } \\
& Lecture & Online & Total \\
\hline Responses & 104 & 88 & 192 \\
$\%>=10$ miles & $23.1 \%$ & $47.7 \%$ & $34.4 \%$ \\
P-value for chi-square test of difference $=<0.0000$. &
\end{tabular}

Tables 2 through 5 clearly support our expectations about why students choose online courses. Students with greater work and childcare responsibilities were more likely to prefer the flexibility of the online mode. And students with greater commuting distances were attracted to the greater convenience offered by the online format.

The last of the observable characteristics relates to the amount of preparation students have for taking a class online. We would expect that students who feel more at ease with the computer would be more likely to enroll in the online section, while those with less experience would gravitate toward the lecture section. Our fourth major question concerned computer experience. Note that the topic of the course is computer programming in $\mathrm{C}++$, so all the students in our sample are likely to have more knowledge of computer use than the average undergraduate. The experience categories were:

- None

- Experience with word processing and/or spreadsheet applications

- Experience with typical software applications plus web page development

- Experience with all of the above plus some programming

- Extensive programming experience

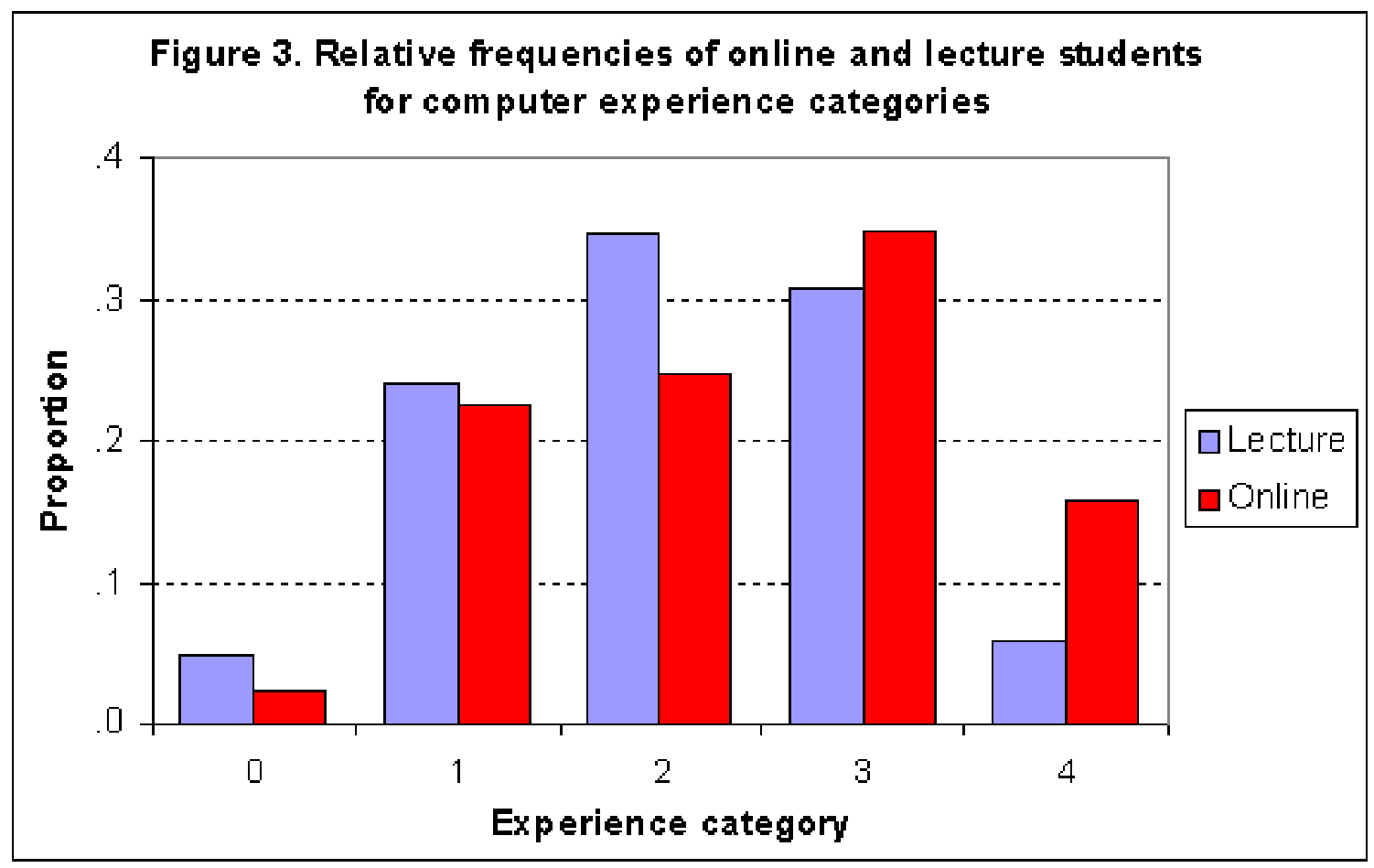


Figure 3 illustrates how each group of students, lecture and online, is split among the five categories. It is apparent that a higher proportion of the online students have more programming experience while a larger proportion of the lecture students report less experience. In order to conduct a simple statistical test, we divided the categories into two groups: 0-2 and 3-4. Although this division is somewhat arbitrary, the information conveyed in Figure 3 indicates that the lecture section contained proportionately more students in the 0-2 categories while the online section had relatively more students in the 3-4 experience categories. The results in Table 6 show a substantially higher computer experience level among the online students. More than half the online students had some previous programming experience (category 3 or 4 ), while only $36.5 \%$ of the lecture students had that level of experience. The difference is statistically significant.

Table 6

Proportion in higher computer experience categories

\begin{tabular}{|c|c|c|c|}
\hline & Lecture & Online & Total \\
\hline Responses & 104 & 89 & 193 \\
\hline$\%$ Category 3 or 4 & $36.5 \%$ & $50.6 \%$ & $43.0 \%$ \\
\hline
\end{tabular}

So far, the results show that online students do differ from lecture students in a number of observable characteristics. The online class had a larger number of older students, students who were not full-time or enrolled in a regular undergraduate degree program, students with greater work and/or childcare responsibilities, and students who had more programming experience.

It would also be useful to know whether students are attracted to online classes because of differences in their own perceived needs. We examine this question in the last section of our survey which contain questions about the importance that various factors played in the choice between the online and lecture versions of the course. A priori, we would expect students who need more structure and interaction to prefer the lecture section while students with needs for greater convenience and flexibility to gravitate to the online section.

Students were asked to rate eleven different factors as "very important," "important," or "not important" in making their choice of class section:

- Opportunity for face-to-face contact with instructor

- Opportunity for face-to-face contact with fellow students

- Conflict between class time and work commitments

- Conflict between class time and childcare commitments

- Course scheduling conflict

- Reduce time commuting to class

- Motivation provided by regular class meetings

- Flexibility in setting pace and time for studying

- Better learning from hearing a lecture

- Better learning from reading the lecture materials

- Advice from advisor or other university official

Table 7 (see end of section) presents the percentage of students responding to each category. The table also contains the results of the chi-square tests to evaluate the differences between the two class sections 
(with the "important" and "very important" percentages combined into one group for purposes of the test). As the results demonstrate, online and lecture students differ significantly in their assessment of the importance of eight of the eleven factors.

Opportunity for face-to-face contact with the instructor and with fellow students, motivation provided by regular class meetings, better learning from hearing a lecture, and advice from advisor or other university official are definitely more important for these lecture students in their survey responses. The first three of these are as predicted. For the fourth one, advice from an official, we had no clear prediction. However, students are less familiar with online courses and may expect these courses somehow to be easier when there is no lecture to attend. Many undergraduates may not be sufficiently prepared to take such courses. So, it would not be surprising if the bulk of official advice cautioned against online instruction.

Conflict between class time and work, time commuting to class, and flexibility in setting pace and time for studying were all significantly more important for online than for lecture students. The results are consistent with our prior expectations, as well as with the results of the tables described above.

Three of the eleven factors showed no significant difference between online and lecture students in their assessment of importance. Conflict between class time and childcare commitments was one of these. The number of students reporting childcare responsibilities was very low, so the test in this case was weak and the results not very meaningful. There was no significant difference between the two groups in the importance they each attributed to course scheduling conflicts and better learning from reading the lecture materials. It is somewhat surprising that course scheduling conflicts were not significantly more important for online students. However, this is likely a result of the fact that many students in the online section were taking only one or two classes. It is not at all surprising that better learning from reading materials was not important, since both groups had equal access to materials for reading. 
JALN Volume 6, Issue 1 - July 2002

Table 7

Importance of various factors in choosing course format

\begin{tabular}{|c|c|c|c|c|c|c|c|}
\hline \multirow{2}{*}{$\begin{array}{l}\text { Question } \\
\text { CHI-Squared: }\end{array}$} & \multicolumn{3}{|c|}{ Face-to-face contact with instructor } & \multirow{2}{*}{$\begin{array}{l}\text { Question } \\
\text { CHI-Squared: }\end{array}$} & \multicolumn{3}{|c|}{ Motivation from regular class meetings } \\
\hline & 32.0533 & P-value: & 0 & & \multirow{2}{*}{$\frac{26.6101}{\text { Lecture }}$} & \multirow{2}{*}{$\frac{\text { P-value: }}{\text { Online }}$} & 0 \\
\hline & Lecture & Online & Total & & & & Total \\
\hline Responses & 104 & 84 & 188 & Responses & 99 & 84 & 183 \\
\hline Not important & $7.7 \%$ & $42.9 \%$ & $23.4 \%$ & Not important & $11.1 \%$ & $60.7 \%$ & $33.9 \%$ \\
\hline Important & $60.6 \%$ & $44.0 \%$ & $53.2 \%$ & Important & $65.7 \%$ & $28.6 \%$ & $48.6 \%$ \\
\hline Very important & $31.7 \%$ & $13.1 \%$ & $23.4 \%$ & Very important & $26.3 \%$ & $7.1 \%$ & $17.5 \%$ \\
\hline Question & \multicolumn{3}{|c|}{ Face-to-face contact with fellow students } & \multirow{2}{*}{$\begin{array}{l}\text { Question } \\
\mathrm{CHI}-S q u a r e d:\end{array}$} & \multicolumn{3}{|c|}{ Flexibility in setting pace \& time of study } \\
\hline \multirow[t]{2}{*}{ CHI-Squared: } & 34.8885 & P-value: & 0 & & 14.0941 & P-value: & 0.0002 \\
\hline & Lecture & Online & Total & & Lecture & Online & Total \\
\hline Responses & 103 & 83 & 186 & Responses & 101 & 85 & 186 \\
\hline Not important & $24.3 \%$ & $67.5 \%$ & $43.5 \%$ & Not important & $24.8 \%$ & $4.7 \%$ & $15.6 \%$ \\
\hline Important & $50.5 \%$ & $27.7 \%$ & $40.3 \%$ & Important & $44.6 \%$ & $38.8 \%$ & $41.9 \%$ \\
\hline Very important & $25.2 \%$ & $4.8 \%$ & $16.1 \%$ & Very important & $30.7 \%$ & $56.5 \%$ & $42.5 \%$ \\
\hline Question & \multicolumn{3}{|c|}{ Conflict between class time and work } & Question & \multicolumn{3}{|c|}{ Better learning from hearing a lecture } \\
\hline \multirow[t]{2}{*}{ CHI-Squared: } & 17.3163 & P-value: & 0 & CHI-Squared: & 52.6826 & P-value: & 0 \\
\hline & Lecture & Online & Total & & Lecture & Online & Total \\
\hline Responses & 99 & 86 & 185 & Responses & 104 & 83 & 187 \\
\hline Not important & $50.5 \%$ & $20.9 \%$ & $36.8 \%$ & Not important & $8.7 \%$ & $57.8 \%$ & $30.5 \%$ \\
\hline Important & $35.4 \%$ & $23.3 \%$ & $29.7 \%$ & Important & $42.3 \%$ & $36.1 \%$ & $39.6 \%$ \\
\hline Very important & $14.1 \%$ & $55.8 \%$ & $33.5 \%$ & Very important & $49.0 \%$ & $6.0 \%$ & $29.9 \%$ \\
\hline Question & \multicolumn{3}{|c|}{ Conflict between class time $\&$ child care } & Question & \multicolumn{3}{|c|}{ Better learning from reading lectures } \\
\hline \multirow[t]{2}{*}{ CHI-Squared: } & 0.1114 & P-value: & 0.7386 & CHI-Squared: & 0.095 & P-value: & 0.758 \\
\hline & Lecture & Online & Total & & Lecture & Online & Total \\
\hline Responses & 95 & 86 & 181 & Responses & 104 & 84 & 188 \\
\hline Not important & $81.1 \%$ & $79.1 \%$ & $80.1 \%$ & Not important & $17.3 \%$ & $19.0 \%$ & $18.1 \%$ \\
\hline Important & $13.7 \%$ & $5.8 \%$ & $9.9 \%$ & Important & $54.8 \%$ & $48.8 \%$ & $52.1 \%$ \\
\hline Very important & $5.3 \%$ & $15.1 \%$ & $9.9 \%$ & Very important & $27.9 \%$ & $32.1 \%$ & $29.8 \%$ \\
\hline Question & \multicolumn{3}{|c|}{ Course scheduling conflict } & Question & \multicolumn{3}{|c|}{ Advice from advisor / university official } \\
\hline \multirow[t]{2}{*}{ CHI-Squared: } & 0.1371 & P-value: & 0.7112 & CHI-Squared: & 5.8235 & P-value: & 0.0158 \\
\hline & Lecture & Online & Total & & Lecture & Online & Total \\
\hline Responses & 100 & 85 & 185 & Responses & 99 & 82 & 181 \\
\hline Not important & $58.0 \%$ & $55.3 \%$ & $56.8 \%$ & Not important & $32.3 \%$ & $50.0 \%$ & $40.3 \%$ \\
\hline Important & $30.0 \%$ & $22.4 \%$ & $26.5 \%$ & Important & $40.4 \%$ & $36.6 \%$ & $38.7 \%$ \\
\hline Very important & $12.0 \%$ & $22.4 \%$ & $16.8 \%$ & Very important & $27.3 \%$ & $13.4 \%$ & $21.0 \%$ \\
\hline Question & \multicolumn{3}{|c|}{ Time commuting to class } & & & & \\
\hline CHI-Squared: & 26.6101 & P-value: & 0 & & & & \\
\hline & Lecture & Online & Total & & & & \\
\hline Responses & 99 & 84 & 183 & & & & \\
\hline Not important & $74.7 \%$ & $36.9 \%$ & $57.4 \%$ & & & & \\
\hline Important & $16.2 \%$ & $34.5 \%$ & $24.6 \%$ & & & & \\
\hline Very important & $9.1 \%$ & $28.6 \%$ & $18.0 \%$ & & & & \\
\hline
\end{tabular}




\section{STUDENT PERFORMANCE}

We turn next to consider student performance. First, we compare the performance levels of students in the two class formats, repeating tests we used in our previous paper. Second, we examine the influence of additional factors and test whether the influence of those factors differs between the online and lecture formats. We measure student performance in three ways: the final exam score, a modified course grade, and the course completion rate. The modified course grade was the weighted average of the class scores, not including the lab average and the homework grade. The lab score was removed because lab assignments differed for the two sections, and the homework grade was removed because we use it as an independent variable to represent effort in explaining performance.

The comparisons between online and lecture students were carried out using Ordinary Least Squares (OLS) regression, a statistical method of estimating the degree to which a given variable is affected by a set of other variables. We estimated two groups of regressions. In one group, we put all the observations together and included the qualitative variable "online" which equaled one for online students and zero for lecture students, in order to distinguish the two groups. These regressions showed the effects of each of the variables on performance of the whole group, and they highlighted the difference in performance between online and lecture students. In other cases we estimated regressions for the online and lecture sub-samples separately. This set of regressions allowed us to compare the two sub-groups in terms of the way the four explanatory variables affected each group's performance.

In a previous study we found that final exam and course grades were positively related to the level of effort the student devoted to the course (as measured by the homework grade) and that non-traditional students did better than regular undergraduates. The exam, course grade, and homework were all measured on a 100-point scale. Using the new data, we expand our earlier work and add a set of additional factors as explanatory variables. Our hypothesis is that performance can be predicted by the amount of effort devoted to completing class assignments (since students could correct and resubmit homework multiple times, a student who was either well-prepared or persistent could get 100 percent of the homework correct), the student's university program (undergraduate vs. lifelong), whether the student worked, and how well prepared the student was to use the computer (since the online format relies heavily on computer use). We also consider the student's age, childcare responsibilities, commuting distance, and gender. We additionally test semester credit hours as an explanatory variable, but it has no predictive value for the course or final exam grade and is therefore not included in the regressions we report here.

Table 8 presents the results of multivariate regressions testing the relationships. The coefficient estimates in bold indicate the effect on performance of a change in each explanatory variable. The numbers beneath each coefficient show the probability of observing the number if in fact the variable had no effect on performance. In earlier work, we focused on whether online students did as well in course performance as lecture students. In that work we found that online students typically did somewhat better. For purposes of comparison, we repeated the tests we performed in our first paper. The results presented in columns one and three are very close to what we found earlier. The new tests indicate that the amount of effort the student devoted to the class positively affected the grade. An additional 10 points on the homework average led to about 4.5 more points on the exam and 5 points in the course grade. This result differed very little between online and lecture students. Undergraduate status $(=1$ if the individual was a regular fulltime undergraduate) had a consistent negative effect on performance. Those students who were not enrolled in a regular undergraduate program tended to outperform traditional undergraduates (by about 12 points on the final exam and 6 points on the course grade), and students in the online class did as well or better (significantly better on the final exam) than the lecture students. 
Table 8

OLS regression coefficients for grades

(Coefficients in bold; figures underneath are p-values)

\begin{tabular}{|c|c|c|c|c|}
\hline & \multicolumn{2}{|c|}{$y=$ final exam } & \multicolumn{2}{|c|}{$y=$ modified course } \\
\hline Intercept & $\mathbf{3 0 . 5 3 1 4}$ & 32.4549 & $\mathbf{3 3 . 6 9 8 0}$ & 36.4793 \\
\hline Homework & $\begin{array}{r}<0.0001 \\
\mathbf{0 . 4 4 6 2} \\
<0.0001\end{array}$ & $\begin{array}{r}0.4499 \\
<0.0001\end{array}$ & $\begin{array}{r}\mathbf{0 . 5 0 3 1} \\
<0.0001\end{array}$ & $\begin{array}{r}0.5119 \\
<0.0001\end{array}$ \\
\hline Undergrad & $\begin{array}{r}-12.0155 \\
0.0001\end{array}$ & $\begin{array}{r}-12.8009 \\
0.0037\end{array}$ & $\begin{array}{r}-6.2651 \\
0.0024\end{array}$ & $\begin{array}{r}-7.7953 \\
0.0120\end{array}$ \\
\hline Experience & & $\begin{array}{l}7.0286 \\
0.0202\end{array}$ & & $\begin{array}{l}3.3001 \\
0.1202\end{array}$ \\
\hline Work & & $\begin{array}{r}-7.7552 \\
0.0228\end{array}$ & & $\begin{array}{r}-3.0162 \\
0.2067\end{array}$ \\
\hline Age & & $\begin{array}{r}-0.0114 \\
0.9674\end{array}$ & & $\begin{array}{r}-0.0735 \\
0.7091\end{array}$ \\
\hline Commute & & $\begin{array}{l}4.2036 \\
0.2268\end{array}$ & & $\begin{array}{l}1.8817 \\
0.4423\end{array}$ \\
\hline Child & & $\begin{array}{r}\mathbf{- 5 . 5 5 9 3} \\
0.2956\end{array}$ & & $\begin{array}{r}-1.5392 \\
0.6809\end{array}$ \\
\hline Female & & $\begin{array}{r}-1.9630 \\
0.5963\end{array}$ & & $\begin{array}{r}\mathbf{- 2 . 5 1 0 0} \\
0.3373\end{array}$ \\
\hline Online & $\begin{array}{l}7.8320 \\
0.0036\end{array}$ & $\begin{array}{l}6.0545 \\
0.0750\end{array}$ & $\begin{array}{l}2.6326 \\
0.1586\end{array}$ & $\begin{array}{l}1.9146 \\
0.4227\end{array}$ \\
\hline $\mathbf{N}$ & 237 & 165 & 237 & 165 \\
\hline R Squared & 0.342 & 0.391 & 0.425 & 0.465 \\
\hline
\end{tabular}

Columns two and four contain the results of tests using all of the explanatory variables. These regressions employed fewer observations because some students failed to respond to all questions. When we included all of the variables, we found most had the impact on performance that we would normally expect, and the effect of online status declined. For example, experience in computing $(=1$ for those reporting at least a moderate amount of programming experience) added several points to the predicted examination and course grade averages, and the 7 point difference for the final exam is significant. This result was surely affected by the fact that this was a computer programming course. Previous programming experience may not have any effect on student performance in another academic subject. Working had a negative effect on performance, lowering the final exam score by nearly 7 points, an effect that was also significant. While childcare responsibilities lowered performance, the effect of this variable as well as those of age, commute and gender, was not significant. When the additional variables were included, the tests also showed that online students outperformed lecture students, but the difference shrank and became statistically insignificant. Perhaps some of the advantage shown by online students in the previous tests was the result of their having greater computer experience and a better capacity to handle outside work. 
Table 9

OLS regression coefficients for grades

(Coefficients in bold; figures underneath are p-values)

\begin{tabular}{|c|c|c|c|c|c|c|c|c|}
\hline & \multicolumn{4}{|c|}{$y=$ final exam } & \multicolumn{4}{|c|}{$y=$ modified course } \\
\hline & Total & Total & Online & Lecture & Total & Total & Online & Lecture \\
\hline \multirow[t]{2}{*}{ Intercept } & 33.9454 & 36.9015 & 37.6737 & 35.6195 & 35.7005 & 36.5405 & 37.5700 & 37.0052 \\
\hline & 0.0002 & 0.0110 & 0.0365 & .0023 & $<0.0001$ & $<0.0001$ & 0.0043 & $<0.0001$ \\
\hline \multirow[t]{2}{*}{ Homework } & 0.4319 & 0.4447 & 0.3970 & 0.4587 & 0.4969 & 0.5006 & 0.4633 & 0.5147 \\
\hline & $<0.0001$ & $<0.0001$ & 0.0125 & $<0.0001$ & $<0.0001$ & $<0.0001$ & 0.0001 & $<0.0001$ \\
\hline \multirow[t]{2}{*}{ Undergrad } & -13.2437 & -16.0676 & -9.1544 & -16.6701 & -7.6216 & -8.4240 & -4.7842 & -10.4709 \\
\hline & 0.0006 & $<0.0001$ & 0.0726 & 0.0057 & 0.0046 & 0.0007 & 0.1894 & 0.0122 \\
\hline \multirow[t]{2}{*}{ Experience } & 7.4341 & 7.6050 & 4.8356 & 8.8840 & 3.6329 & 3.6814 & 1.5785 & 4.8627 \\
\hline & 0.0123 & 0.0110 & 0.2230 & 0.0380 & 0.0801 & 0.0756 & 0.5783 & 0.1009 \\
\hline \multirow[t]{2}{*}{ Work } & -7.2400 & -6.9088 & -0.1758 & -10.0779 & -2.9559 & -2.8618 & 0.9439 & -4.5071 \\
\hline & 0.0266 & 0.0354 & 0.9741 & 0.0183 & 0.1953 & 0.2086 & 0.8088 & 0.1259 \\
\hline \multirow[t]{2}{*}{ Online } & 6.1784 & & & & 1.7556 & & & \\
\hline & 0.0611 & & & & 0.4467 & & & \\
\hline $\mathbf{N}$ & 166 & 166 & 69 & 97 & 166 & 166 & 69 & 97 \\
\hline R Squared & 0.381 & 0.367 & 0.252 & 0.334 & 0.459 & 0.457 & 0.33 & 0.461 \\
\hline
\end{tabular}

Because we had several variables that appeared to contain little explanatory power, we decided to run the regressions again keeping only those variables that were significant in at least one test. The results in Columns 1 and 5 of Table 9 are similar to those presented above. The coefficients on undergraduate status and effort continued to be positive and significant regardless of the performance measure used, and the final exam score was still positively related to prior experience. The coefficient estimates for online status were positive but only marginally significant for the final exam and not significant for course grade.

For purposes of comparing the effect of the variables on each of the two groups, we present the coefficient estimates for the same regressions run on the online and lecture sections separately. Although in general each variable in these affected both online and lecture students' performance in the same direction, the impact was greater for students in the lecture section. For example, undergraduate status lowered the final exam score by 7.5 points more for lecture than for online students and the course grade by almost 6 points more. Work status had a large (10 points) and significant negative effect on exam grade for lecture students, but only a small ( 0.18 points) and statistically insignificant effect for online students. Work also lowered the modified course grade by 4.5 points for lecture students and raised it by 0.94 points for online students, but neither effect was statistically significant.

The differences between the point estimates for the two groups seem quite large. Some of the coefficients for the lecture group were two or more times as large as those for the online group. We tested the coefficients both as a group and individually to determine whether there was a significant difference between them for the lecture and online students. Surprisingly, we could not reject the hypothesis that the coefficients (the effects of the variables on performance) were the same for both the lecture and the online sub-samples. 
Table 10

Logit coefficients; limited dep. variable $=$ finished

(Coefficients in bold; underneath are p-values and marginal probability

effects.)

\begin{tabular}{lccccc} 
& Total & Total & Total & Online & Lecture \\
\hline Intercept & - & - & - & - & - \\
p- & 0.0001 & $<0.000$ & $<0.000$ & $<0.000$ & 0.0376 \\
Homework & $\mathbf{0 . 0 8 8 9}$ & $\mathbf{0 . 0 9 0 6}$ & $\mathbf{0 . 0 9 2 1}$ & $\mathbf{0 . 1 1 6 0}$ & $\mathbf{0 . 0 7 1 5}$ \\
p- & $<0.000$ & $<0.000$ & $<0.000$ & $<0.000$ & $<0.000$ \\
prob & 0.0121 & 0.0123 & 0.0125 & 0.0158 & 0.0097 \\
Semester & & $\mathbf{0 . 2 0 5 8}$ & $\mathbf{0 . 1 8 0 3}$ & $\mathbf{0 . 2 5 7 0}$ & $\mathbf{0 . 1 0 9 5}$ \\
p- & & 0.0230 & 0.0070 & 0.0109 & 0.3050 \\
prob & & 0.0280 & 0.0245 & 0.0350 & 0.0149 \\
Undergrad & $\mathbf{1 . 1 4 2 0}$ & - & & & \\
p- & 0.0991 & 0.6645 & & & \\
prob & 0.1554 & - & & & \\
Online & - & - & - & & \\
p- & 0.0130 & 0.1444 & 0.1498 & & \\
prob & - & - & - & & \\
$\mathbf{N}$ & 283 & 283 & 283 & 131 &
\end{tabular}

In addition to looking at the final exam score and course grade, we also considered completion of the course as a sign of success. Of the 283 students who began the course (defined as still being enrolled at the end of the official drop period), 237 took the final exam and 46 failed to do so. Table 10 contains the results of logit regressions that use course completion as the binary dependent variable. That variable is defined to take on a value of 1 for those who finished and 0 for those who did not. The coefficients from a logit regression indicate the effects of the explanatory variables on the log of the odds (for example, oneto-four or three-to-two) of completing the course. From these coefficient values we can also derive the effects of the explanatory variables on the probability (for example, a 20 percent chance or 50 percent chance) of completing the course and we focus on them because they are intuitively easier to interpret. The probability effects are not constant since they depend on the values of the explanatory variables. We follow the convention of using the mean values of the explanatory variables in the computations. There are three sets of values reported in Table 10: each variable's logit coefficient, the p-value associated with that coefficient, and the variable's effect on the probability of completing the course. We had initially used a larger set of variables in the logit regressions, but these variables had such high p-values that we decided not to include them in the set of regressions reported here.

We tried several predictors of course completion. The first set is the same as what we used in our previous paper, homework grade, undergraduate status, and section (online or lecture). As in our previous results, online status had a significant negative effect on probability of completion. Online status decreased probability of completion by 20 percentage points. Also, homework completion had a significant positive effect (increasing the probability of completion by about 1.2 percentage points for each additional homework point) and undergraduate status had a marginally significant positive effect (with undergraduates having about $15 \%$ more probability of completion than others).

In the second regression we added semester hours enrolled as an explanatory variable and found hours to 
have a significant positive effect on probability of completion (with each semester hour adding about 2.8 percentage points to the probability of finishing). Also, when we added hours the effect of undergraduate status changed sign and was no longer even marginally significant. In addition, online status was no longer a significant predictor of completion. Undergraduate status and semester hours are likely measuring similar things; because hours taken provide more explanation, we dropped undergraduate status from the rest of the regression equations.

To compare the effects of the explanatory variables on completion by the two sections, we estimated the last two regressions for online and lecture students separately. Homework and semester hours were the explanatory variables. Homework grade showed significant positive effects for both groups, though a little stronger for the online group. Semester hours was a significant predictor of course completion for online students but not for lecture students taken alone.

In our earlier paper we suggested that traditional undergraduates have a stronger motivation to stick with a course. Nontraditional students not working for a degree have less at stake, know less about the course before signing up, and are perhaps more likely than traditional undergraduates to have unforeseen problems arise. The results of the present paper suggest a slight change in this interpretation. Rather than undergraduate status, it is academic load that helps explain course completion. Students taking more semester hours were significantly more likely to complete the course, whether they were in undergraduate degree programs or not. Apparently students with a light academic load were less committed to completion, no matter what their degree status.

\section{SUMMARY AND CONCLUSION}

In this paper we have tried to identify the characteristics that differentiate students taking an online course from students taking the same course in a lecture format. We find that the two groups differed in several important respects. Online students are older. They are less likely to be enrolled in traditional undergraduate programs and more likely to be lifelong learning students. They are more likely to have job and/or childcare responsibilities and longer average commutes to campus. And they are more experienced with computers.

In addition, online students rate class conflict with work, reducing commuting time, and flexibility in studying as being more important to them in their choice of course format than do lecture students. Lecture students, on the other hand, rate contact with instructors and fellow students, motivation from class meetings, and need to hear a lecture as more important to them. Lecture students also more frequently report advice from university advisors as being important in their choice of format.

We also examine differences in performance levels for the two class formats. We reconfirm results from an earlier study which showed that online students made significantly higher exam grades than lecture students. Course grades for online students are higher, but the effect is not significant. We also reconfirm that homework completion had a positive impact on grades and course completion for both online and lecture students. In addition, undergraduates tend to earn lower grades than students not working on particular undergraduate degrees.

In the current study we add several new explanatory variables. Of these, we find that two significantly affected performance. Working lowered grade performance, while prior computer experience improved students' grade performance. Adding these two variables reduces the importance of online status in affecting grades. 
To explore the differences between online and lecture students, we broke the sample into online and lecture subgroups and analyzed performance separately. We found undergraduate status, work status, and computer experience had larger effects on lecture than on online students. However, the differences in these effects were not statistically significant.

In a set of logit regressions we found that online students were less likely to complete the course. However, when we used enrolled semester hours as an additional explanatory variable, the effect of online status on probability of completion was no longer statistically significant. Other explainers of the probability completion included homework grade (always showing a significant positive effect), enrolled semester hours (also showing a significant positive effect), and undergraduate status (showing a marginally significant positive effect only when the semester hour variable was not included in the regression). When the sample was split into separate regressions for online and lecture students, the effects remained qualitatively similar except that semester hours was no longer significant for lecture students.

These results largely accord with our expectations. We are somewhat surprised in explaining that age had so little effect on performance, or that commuting or childcare situation appear unimportant.

Our results contribute substantially, we believe, to understanding this new portion of the educational landscape. However, we are also aware that we are working with a special set of data. Because of the nature of the subject matter, the students in both the online and lecture sections had more technical training and computer experience than many of the students who might consider taking online classes in other disciplines. An important extension of this research will be to examine other cases of side by side online and lecture sections to see whether the results we have obtained here are observed in other types of courses.

\section{ACKNOWLEDGEMENTS}

We would like to thank Burks Oakley and several anonymous referees for helpful advice for this paper.

\section{APPENDIX: SURVEY FORM}

NAME:

SS\#:

LOCAL TELEPHONE \#:

EMAIL:

1. Will you be working this semester?

Yes No

a. If yes, how many hours per week, on average?

b. If yes, what is the nature of the work?

2. Will you have childcare responsibilities this semester? Yes No 
a. If yes, how many hours per week, on average?

3. How many miles do you commute from your house to campus (one way)?

$0-10$

$10-50$

More than 50

4. Which of the following best describes your computer experience?

None

Experience with word processing and/or spreadsheet applications

Experience with typical software applications plus web page development

Experience with all of the above plus some programming

Extensive programming experience

5. In which section of CSC 114 are you currently enrolled?

Lecture Online

6. In choosing the section in which you are enrolled (lecture vs. online), please rate the importance of the following factors.

$\mathrm{N}=$ Not important $\quad \mathrm{I}=$ Important $\quad \mathrm{V}=$ Very important

Opportunity for face-to-face contact with instructor

Opportunity for face-to-face contact with fellow students

Conflict between class time and work commitments

Conflict between class time and childcare commitments

Course scheduling conflict

Reduce time commuting to class

Motivation provided by regular class meetings

Flexibility in setting pace and time for studying

Better learning from hearing a lecture

Better learning from reading the lecture materials

Advice from advisor or other university official

Other (Please explain)

\section{REFERENCES}

1. Boulet, M. and Boudreault, S. Using Technology to Deliver Distance Education in Computer Science. Journal of Engineering Education, Vol. 87, No.4, pp 433-436, October, 1998.

2. Davis, J. L. Computer-Assisted Distance Learning, Part II: Examination Performance of Students On and Off-Campus. Journal of Engineering Education, Vol. 85, No.1, pp 77-82, January 1996.

3. Dutton, J., Dutton, M. and Perry, J. Do Online Students Perform as Well as Lecture Students? Journal of Engineering Education, Vol. 90, No. 1, pp 131-136, January 2001. 
4. Liu, X., MacMillan, R. and Timmons, V. Assessing the Impact of Computer Integration on Students, Journal of Research on Computing in Education, Vol. 31, No. 2, pp 189-203, Winter 1998.

5. Navarro, P. and Shoemaker, J. Policy Issues in the Teaching of Economics in Cyberspace: Research Design, Course Design, and Research Results. Contemporary Economic Policy, Vol. 18, No. 3, pp 359-366, July, 2000.

6. Russell, T. L. The No Significant Difference Phenomenon, North Carolina State University, Raleigh, NC, 1999.

7. Smeaton, A. F. and Keogh, G. An Analysis of the Use of Virtual Delivery of Undergraduate Lectures, Computers and Education, Vol. 32, No. 1, pp 83-94, 1998.

8. Spooner, F., Jordan, L., Algozzine, B. and Spooner, M. Student Ratings of Instruction in Distance Learning and On-Campus Classes, Journal of Educational Research, Vol. 92, No. 3, pp 132-140, January/February, 1999.

9. Snell, J. and Mekies, S. Online Education and Academic Rigor: a Research Note. Journal of Instructional Psychology, Vol. 26, No. 3, pp 194-195, September, 1999.

10. Bengiamin, N., Johnson, A., Zidon, M., Moen, D. and Ludlow, D. The Development of an Undergraduate Distance Learning Engineering Degree for Industry - A University/Industry Collaboration. Journal of Engineering Education, Vol. 87, No. 3, pp 277-282, July, 1998.

11. Wallace, D. and Mutooni, P. A Comparative Evaluation of World Wide Web-Based and Classroom Teaching, Journal of Engineering Education, Vol. 86, No. 3, pp. 211-219, 1997.

\section{SECONDARY RESOURCES}

12. Fan, T., Li, Y. and Niess, M. L. Predicting Academic Achievement of College Computer Science Majors. Journal of Research on Computing in Education, Vol. 31, No. 2, pp 155-172, Winter 1998.

13. Ward, M. and Newlands, D. Use of the Web in Undergraduate Teaching, Computers and Education, Vol. 31, No. 2, pp 171-184, September, 1998.

14. Zandvliet, D. and Farragher, P. A Comparison of Computer-Administered and Written Tests. Journal of Research on Computers in Education, Vol. 29, No. 4, pp 423-438, Summer 1997.

\section{ABOUT THE AUTHORS}

Dr. John Dutton received his Ph.D. in Economics from Duke University in 1978. He teaches international financial management and business statistics in the Department of Business Management, College of Management, of North Carolina State University. His research interests include issues of education technology and issues of international finance.

Address: Department of Business Management, P.O. Box 7229, North Carolina State University, Raleigh, North Carolina 27695-7229; telephone 919 515-6948; fax: 919 515-6943; email: john_dutton@ncsu.edu.

Dr. Marilyn M. Dutton received her Ph.D. in Economics from Duke University in 1989. She is currently an associate professor of finance in the School of Business at North Carolina Central University. Her research interests include the factors that affect students' academic performance.

Address:School of Business, P.O. Box 19407, North Carolina Central University, Durham, NC 27707; Telephone: 919-530-7390; fax: 919-560-6163; e-mail: mdutton@nccu.edu.

Dr. Jo Perry received her Ph.D, in mathematics from North Carolina State University in 1972. She taught in the Computer Science Department at NCSU from 1983 - 2000. Her pedagogical interests focused on the freshman and sophomore programming courses, bringing the introductory $\mathrm{C}++$ course online in 1997. She recently left academia to work for TogetherSoft Corporation.

Address: TogetherSoft, 920 Main CampusDrive Suite 410, Raleigh, NC 27606; telephone 919 833-5550; fax: 919 833-5533; email: jo.perry@togethersoft.com 